Arzt E, Bronstein M, Guitelman M (eds): Pituitary Today: Molecular, Physiological

and Clinical Aspects. Front Horm Res. Basel, Karger, 2006, vol 35, pp 135-142

\title{
Gene Therapy in the Neuroendocrine System
}

\author{
C.B. Hereñú, G.R. Morel, M.J. Bellini, P.C. Reggiani, Y.E. Sosa, \\ O.A. Brown, R.G. Goya \\ Institute for Biochemical Research-Histology B, Faculty of Medicine, National \\ University of La Plata, La Plata, Argentina
}

\begin{abstract}
The implementation of experimental gene therapy in animal models of neuroendocrine diseases is an area of growing interest. In the hypothalamus, restorative gene therapy has been successfully implemented in Brattleboro rats, an arginine vasopressin (AVP) mutant which suffers from diabetes insipidus, and in Koletsky $\left(\mathrm{fa}^{\mathrm{k}} / \mathrm{fa}^{\mathrm{k}}\right)$ and in Zucker $(f a / f a)$ rats which have leptin receptor mutations that render them obese, hyperphagic and hyperinsulinemic. In the above models, viral vectors expressing AVP, leptin receptor $\mathrm{b}$ and proopiomelanocortin, respectively, were stereotaxically injected in the relevant hypothalamic regions. In rats, aging brings about a progressive degeneration and loss of hypothalamic tuberoinfundibular dopaminergic (TIDA) neurons, which are involved in the tonic inhibitory control of prolactin secretion and lactotropic cell proliferation. Stereotaxic injection of an adenoviral vector expressing insulin-like growth factor I corrected their chronic hyperprolactinemia and restored TIDA neuron numbers. Spontaneous intermediate lobe pituitary tumors in a retinoblastoma $(\mathrm{Rb})$ gene mutant mouse were corrected by injection of an adenoviral vector expressing the human $\mathrm{Rb}$ cDNA and experimental prolactinomas in rats were partially reduced by intrapituitary injection of an adenoviral vector expressing the HSV1-thymidine kinase suicide gene. These results suggest that further implementation of gene therapy strategies in neuroendocrine models may be highly rewarding.
\end{abstract}

Copyright (C) 2006 S. Karger AG, Basel

Gene therapy, the transfer of genetic material for therapeutic purposes, has undergone an explosive development in the last decade. Current molecular biology technology has made it possible to consider as feasible genetic manipulations that would have been deemed utopic not too long ago. Particularly important advances are being made in the improvement of gene transfer technology. Current efforts for the development of more efficient viral vectors focus 
on two main objectives, namely the achievement of cell-type specificity for transgene delivery and the design of vectors where, once the transgene is incorporated into the target cell, its expression can be regulated by small molecules.

Gene transfer to the central nervous system (CNS) poses significant challenges due to both the relative inaccessibility of the brain and spinal cord and the extraordinary complexity of CNS structures. On the other hand, this approach offers unique advantages for the effective delivery of therapeutic molecules to specific CNS regions affected by tumors, neurodegenerative processes or genetic defects.

Although a great deal of research efforts are been devoted to developing gene therapy strategies for neurological diseases [1], most of the work has been done in non-diencephalic brain regions. Much less work has been performed in the neuroendocrine system despite the unique advantages that it offers for the assessment of in vivo gene therapy strategies. In this article we will evidence these advantages by reviewing the core of documented studies in which in vivo gene therapy has been implemented in the neuroendocrine system of rodent models.

\section{In vivo Gene Therapy in the Hypothalamus}

\section{Brattleboro Rat}

The first animal model in which gene therapy was implemented in the hypothalamus was the Brattleboro rat. This mutant contains a single basepair mutation in the arginine vasopressin (AVP) gene which results in a highly conspicuous diabetes insipidus (DI) phenotype characterized by the production of large volumes of hypo-osmotic urine and compensatory polydipsia [2]. An adenoviral vector (AdAVP) encoding the rat AVP cDNA under the control of the cytomegalovirus (CMV) promoter was used in this animal model. When AdAVP was stereotaxically injected into the substantia innominata (a non-AVP producing hypothalamic area) of normal Wistar-Kyoto rats, expression of AVP mRNA was detected from 7 days to 6 months postinjection [3]. Injection of AdAVP into the supraoptic nucleus (SON, where part of the magnocellular neurons that produce AVP in normal animals lie) of Brattleboro rats resulted in substantial expression of AVP in magnocellular cells as well as in the presence of immunohistochemically detectable AVP in their axons projecting to the posterior pituitary. Measurement of urine output and urine osmolality showed that the symptoms of DI in the Brattleboro rats were significantly reduced for up to 4 months after injection of the viral vector [3]. An equine infectious anemia viral (EIAV) vector expressing AVP was injected into the hypothalamic supraoptic nuclei of Brattleboro rats resulting in expression of functional AVP peptide in magnocellular neurons. This was accompanied by a $100 \%$ recovery 
in water homeostasis as assessed by daily water intake, urine production, and urine osmolality lasting for at least 1 year [4].

\section{Mutant Leptin Receptor Rat Models}

Rat models of leptin receptor deficiency have been used to explore the restorative effect of gene therapy in the hypothalamus of these obese animals. In one study [5], leptin receptor defective Koletsky rats $\left(\mathrm{fa}^{\mathrm{k}} / \mathrm{fa}^{\mathrm{k}}\right)$ were used. These animals received in the arcuate (ARC) nucleus a bilateral $0.5-\mu$ l injection containing either an adenoviral vector (Ad-lepr $r^{b}$ ) expressing the signaling isoform of the leptin receptor lepr ${ }^{\mathrm{b}}\left(2.4 \times 10^{12} \mathrm{pfu} / \mathrm{ml}\right)$ or an Ad vector (Ad-lacZ) expressing the $\beta$-galactosidase $\left(\beta\right.$-gal) reporter gene $\left(1.7 \times 10^{12} \mathrm{pfu} / \mathrm{ml}\right)$. Sixteen days postinjection, Ad-lepr ${ }^{b}$ - but not Ad-lacZ-injected animals showed restored lepr ${ }^{b}$ mRNA levels (which are low in control mutants) in the ARC nucleus. Restored leptin receptor expression reduced both mean daily food consumption (13\%) and body weight gain $(33 \%)$. It also increased hypothalamic pro-opiomelanocortin (POMC) mRNA levels (65\%) while decreasing neuropeptide Y mRNA levels by $30 \%$, relative to Ad-lacZ-injected mutants. In contrast, Ad-lepr ${ }^{b}$ injection in the ARC nucleus of wild-type animals had no effect on the above parameters.

A similar experimental approach was implemented in Zucker $(f a / f a)$ rats which are obese, hyperphagic and hyperinsulinemic as a consequence of a mutation in their leptin receptor. These animals received in the ARC nucleus a stereotaxic bilateral injection $\left(3 \mu \mathrm{l} /\right.$ side; $1.28 \times 10^{9}$ particles $)$ of either a recombinant adeno-associated viral (rAAV) vector expressing murine POMC (rAAV-POMC) or a rAAV expressing enhanced green fluorescent protein (rAAV-eGFP). At day 38 postinjection, the rAAV-POMC-injected animals showed a 4-fold increase in hypothalamic POMC expression and a $62 \%$ increase in melanocortin signaling (indicated by phosphorylation of the cAMP response element binding protein, CREB), relative to $\mathrm{rAAV}-\mathrm{eGFP}$-injected animals. A sustained reduction in food intake, weight gain and visceral adiposity was also observed in the experimental animals. POMC transgene delivery also increased the uncoupling of brown adipose tissue (BAT) protein. Circulating leptin, cholesterol and insulin were reduced in the rAAV-POMC-injected animals receptor [6].

Taken together these leptin receptor studies further demonstrate the suitability of the hypothalamus for the implementation of restorative gene therapy in mutant animal models.

\section{Aging Female Rat}

The dopaminergic (DA) neurons of the rat hypothalamus are grouped into two main areas, $\mathrm{A}_{12}$ and $\mathrm{A}_{14}[7,8]$, with the DA perikarya of the $\mathrm{A}_{12}$ area being located in the ARC nucleus and in the periarcuate region [9]. The $\mathrm{A}_{14}$ DA neurons are mainly located within the paraventricular $(\mathrm{PaV})$ and periventricular $(\mathrm{PeV})$ 
nuclei, with a few scattered DA neurons in the anterior ventromedial (AVM) hypothalamic area $[9,10]$. The $A_{12}$ area and its corresponding axon terminals constitute the tuberoinfundibular dopaminergic (TIDA) system, whereas the $\mathrm{A}_{14}$ area and its fibers are known as the periventricular dopaminergic (PVDA) system. Both systems regulate prolactin (PRL) secretion by exerting a tonic inhibitory control on both PRL secretion and lactotrope proliferation [11]. In early studies, TIDA neuron function was reported to decline during aging in rats, with a marked reduction in hypothalamic, median eminence and neurointermediate lobe DA content in old (24-26 months) as compared with young (4 months) rats [12]. More significant, the rate of DA secretion into the hypophysial portal blood of aged (20-26 months) male and female rats was found to decline drastically when compared with young (2-4 months) counterparts [13,14]. Although the above age-related alterations in hypothalamic DA secretion were ascribed to a functional decline of TIDA neurons rather than to TIDA neuron loss [12], more recent work in very old female rats (32 months) showed that at extreme ages, DA neuron loss occurs in the rat hypothalamus, particularly in the $\mathrm{PaV}$ nucleus [15]. The degeneration and loss of TIDA neurons during normal aging is associated, in the female rat, with progressive hyperprolactinemia [16] and the development of pituitary prolactinomas [17]. Interestingly, parkinsonian patients usually reveal functional alterations in the hypothalamo-PRL axis [18].

It should be pointed out that although a number of in vivo models have been developed for the study of the pathophysiology of Parkinson disease (PD) as well as for the assessment of new therapeutic strategies for this devastating pathology [19], they share a significant limitation namely, that the neurological lesions they study are caused by experimental manipulations rather than by aging, the only unequivocal risk factor for PD [20, 21]. In this context, the aging female rat emerges as an interesting model of spontaneous and progressive central DAergic dysfunction. Besides, the functional status of TIDA neurons can be readily and humanely monitored in the animals by measuring circulating PRL levels.

A protective effect of insulin-like growth factor-I (IGF-I) gene transfer has been reported in human DA cell cultures exposed to the toxin salsolinol [22]. In vivo, restorative IGF-I gene therapy was implemented in young (5 months) and senile (28 months) female rats, which received a single intrahypothalamic injection of $3 \times 10^{9} \mathrm{pfu}$ of adenoviral vectors expressing either the reporter gene for $\beta$-gal or rat IGF-I (control and experimental group, respectively) and were sacrificed 17 days postinjection (fig. 1). In the young animals, neither vector modified serum PRL levels but in the IGF-I vector-injected senile rats a nearly full reversion of their hyperprolactinemic status was recorded. Morphometric analysis revealed a significant increase in the total number of tyrosine hydroxylase (TH)-positive cells in the hypothalamus of experimental as compared with control senile animals 


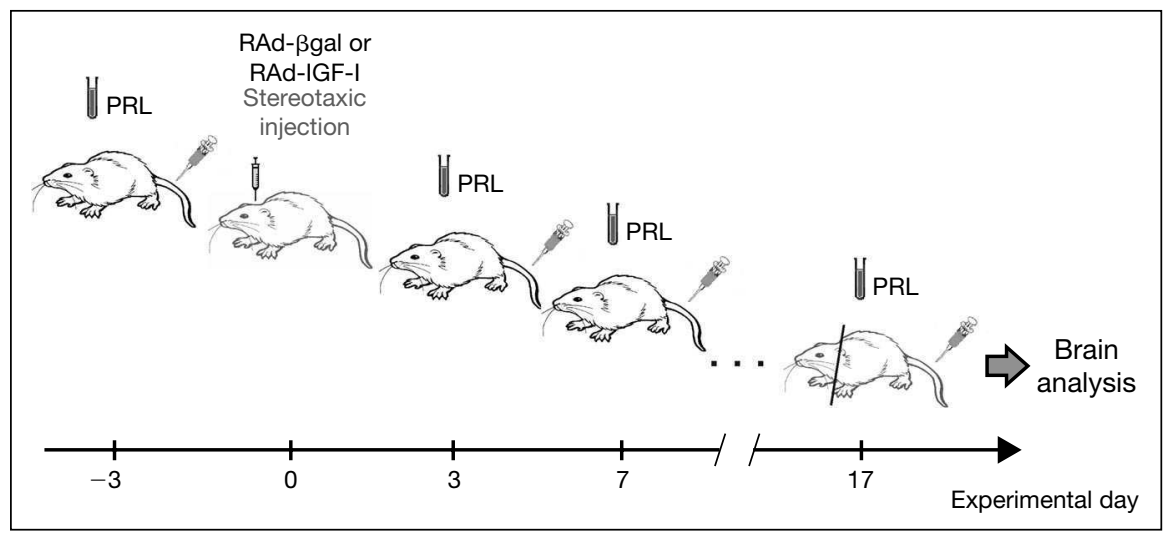

Fig. 1. Proposed experimental design for medium-term IGF-I gene therapy in the hypothalamus of senile female rats with TIDA neurodegeneration. All animals are bled from the tail veins at experimental days $-3,3,7,10,14$ and 17, in order to monitor serum PRL levels. RAd- $\beta$-gal (controls) or RAd-IGF-I (experimental) are stereotaxically injected in the hypothalamus of young and senile females on experimental day 0 . At experimental day 17 (end of treatment) animals are sacrificed and brains removed for biochemical (e.g. transgenic protein content, dopamine and dopamine metabolites content, $\mathrm{TH}$ protein content), and morphometric assessment of hypothalami (e.g. $\mathrm{TH}+, \mathrm{NeuN}+, \mathrm{CD} 11+$ cell morphometric assessment).

$[23,24]$. These results indicate that IGF-I gene therapy in senile female rats is highly effective for reversing their hypothalamic DAergic neurodegeneration.

\section{In vivo Gene Therapy in the Pituitary Gland}

\section{Retinoblastoma Mutant Mouse}

Another type of neuroendocrine model used to implement corrective gene therapy is that based on the transfer of a gene(s) with the ability to rescue the normal phenotype of pituitary tumor cells. This approach has been implemented in mice heterozygous for the retinoblastoma $(\mathrm{Rb})$ tumor suppressor gene $\left(R b^{+/-}\right.$mice). Such mice develop and succumb to characteristic pituitary intermediate lobe melanotrope tumors [25]. Transduction of tumor melanotropic cells with a recombinant adenoviral vector (rAd5.R.Rb) carrying the human $\mathrm{Rb}$ cDNA under the control of its own promoter showed a high level of efficiency both in vitro and in vivo [26]. Furthermore, intracranial delivery of this vector to mice carrying actively growing melanotropic tumors significantly reduced tumor growth and prolonged animal survival. Melanotropic tumor proliferative index and apoptotic rates were markedly lowered in the rAd5.R.Rb-treated 
animals, which also showed growth-inhibitory dopaminergic neuron reinnervation of melanotropic cells [26].

\section{Suicide Gene Therapy in Experimental Pituitary Tumors}

An adenoviral vector, RAdTK, harboring the herpes simplex type 1 thymidine kinase (HSV-1 TK) suicide gene under the control of the human CMV promoter has been used to transfer the TK gene to $\mathrm{GH}_{3}$ and $\mathrm{AtT}_{20}$ rodent pituitary cell lines. Incubation of RAdTK-treated $\mathrm{GH}_{3}$ and $\mathrm{AtT}_{20}$ cells with the prodrug ganciclovir (which after phosphorylation by viral TK becomes toxic) caused total destruction of the cultures [27]. In the same study, estrogen-induced rat prolactinomas were stereotaxically injected with the same RAdTK. Subsequent injection of the host animals with two daily i.p. doses of $25 \mathrm{mg}$ ganciclovir $/ \mathrm{kg}$ for 7 days partially succeeded in reducing AP tumor size and serum PRL levels.

\section{Concluding Remarks}

The implementation of experimental gene therapy in neuroendocrine models has revealed a number of advantages of this system for in vivo studies. The more relevant of these advantages is that the effectiveness and long-term duration of the treatment can be readily monitored by measuring hormone levels or other peripheral variables regulated by the neuroendocrine system. The agerelated degeneration of TIDA neurons in female rats offers a unique animal model for the assessment of neuroprotective gene therapy strategies for PD. Further implementation of gene therapy strategies in neuroendocrine models may prove to be highly rewarding.

\section{Acknowledgements}

This work was supported in part by grants PICT13588 and PICT10663 from the (Argentine) National Agency for the Promotion of Science and Technology (ANPCyT) and grant NIH\#1 R21 TW006665 from the Fogarty International Center and the National Institute on Aging (USA) to R.G.G. R.G.G. and O.A.B. are Research Career scientists of the Argentine Research Council (CONICET). C.B.H. is a doctoral fellowship recipient from CONICET, P.C.R. and G.R.M. are doctoral fellowship recipients from ANPCyT and M.J.B. is a postdoctoral fellowship recipient from NIH.

\section{References}

1 Lowenstein PR, Castro MG: Recent advances in the pharmacology of neurological gene therapy. Curr Opin Pharmacol 2004;4:91-97. 
2 Valtin H: Genetic models of diabetes insipidus; in Windhager EE (ed): Handbook of Physiology. New York, Oxford University Press, 1992, pp 1281-1316.

3 Geddes BJ, Harding TC, Lightman SL, Uney JB: Long-term gene therapy in the CNS: reversal of hypothalamic diabetes insipidus in the Brattleboro rat by using an adenovirus expressing arginine vasopressin. Nat Med 1997;3:1402-1404.

4 Bienemann AS, Martin-Rendon E, Cosgrave AS, Glover CP, Wong LF, Kingsman SM, Mitrophanous KA, Mazarakis ND, Uney JB: Long-term replacement of a mutated nonfunctional CNS gene: reversal of hypothalamic diabetes insipidus using an EIAV-based lentiviral vector expressing arginine vasopressin. Mol Ther 2003;7:588-596.

5 Morton GJ, Niswender KD, Rhodes CJ, Myers MG Jr, Blevins JE, Baskin DG, Schwartz MW: Arcuate nucleus-specific leptin receptor gene therapy attenuates the obesity phenotype of Koletsky $\left(\mathrm{fa}^{\mathrm{k}} / \mathrm{fa}^{\mathrm{k}}\right)$ rats. Endocrinology 2003;144:2016-2024.

6 Li G, Mobbs CV, Scarpace PJ: Central pro-opiomelanocortin gene delivery results in hypophagia, reduced visceral adiposity, and improved insulin sensitivity in genetically obese Zucker rats. Diabetes 2003;52:1951-1957.

7 Dahlström A, Fuxe K: Evidence for the existence of monoamine containing neurons in the central nervous system. I. Demonstration of monoamines in the cell bodies of brain stem neurons. Acta Physiol Scand 1964;62:1-55.

8 Tillet Y, Kitahama K: Distribution of central catecholaminergic neurons: a comparison between ungulates, humans and other species. Histol Histopathol 1998;13:1163-1177.

9 Kawano H, Daikoku S: Functional topography of the rat hypothalamic dopamine neuron systems: retrograde tracing and immunohistochemical study. J Comp Neurol 1997;265:242-253.

10 Goudreau JL, Lindley SE, Lookingland KJ, Moore KE: Evidence that hypothalamic periventricular dopamine neurons innervate the intermediate lobe of the rat pituitary. Neuroendocrinology 1992;56:100-105.

11 Ben-Jonathan N, Arbogast LA, Hyde JF: Neuroendocrine regulation of prolactin release. Prog Neurobiol 1989;33:399-477.

12 Porter JC, Nansel DD, Gudelsky GA, Reymond MJ, Pilotte NS, Foreman MM, Tilders FJH: Some aspects of hypothalamic and hypophysial secretion in aging rats. Peptides 1980;1:135-139.

13 Reymond MJ, Porter JC: Secretion of hypothalamic dopamine into pituitary stalk blood of aged female rats. Brain Res Bull 1981;7:69-73.

14 Gudelsky GA, Nansel DD, Porter JC: Dopaminergic control of prolactin secretion in the aging male rat. Brain Res 1981;204:446-450.

15 Sánchez HL, Silva LB, Portiansky EL, Goya RG, Zuccolilli GO: Impact of very old age on hypothalamic dopaminergic neurons in the female rat: a morphometric study. J Comp Neurol 2003;458:319-325.

16 Goya RG, Lu JKH, Meites J: Gonadal function in aging rats and its relation to pituitary and mammary pathology. Mech Age Dev 1990;56:77-88.

17 Cónsole G, Gómez-Dumm CL, Brown OA, Goya RG: Sexual dimorphism in the age-changes of the pituitary lactotrophs in rats. Mech Age Dev 1997;95:157-166.

18 Franceschi M, Camerlingo M, Perego L, Bottacchi E, Mamoli A: Tubero-infundibular dopaminergic function in Parkinson's disease. Eur Neurol 1988;28:117-119.

19 Shimohama S, Sawada H, Kitamura Y, Taniguchi T: Disease model: Parkinson's disease. Trends Mol Med 2003;9:360-365.

20 de Rijk MC, Breteler MM, Graveland GA, Ott A, Grobbee DE, van der Meche FG, Hofman A: Prevalence of Parkinson's disease in the elderly: the Rotterdam study. Neurology 1995;45: 2143-2146.

21 Mayeux R, Marder K, Cote LJ, Denaro J, Hemenegildo N, Mejia H, Tang MX, Lantigua R, Wilder D, Gurland B: The frequency of idiopathic Parkinson's disease by age, ethnic group and sex in northern Manhattan, 1988-1993. Am J Epidemiol 1995;142:820-827.

22 Shavali S, Ren J, Ebadi M: Insulin-like growth factor-1 protects human dopaminergic SH-SY5Y cells from salsolinol-induced toxicity. Neurosci Lett 2003;340:79-82.

23 Hereñú CB, Cristina C, Rimoldi OJ, Becú-Villalobos D, Goya RG: Construction and use of an adenoviral vector to express transgenic insulin-like growth factor I in the arcuate nucleus and substantia nigra of young and old rats (abstract). 12th International Congress of Endocrinology, Lisbon, 2004. 
24 Hereñú CB, Cristina C, Rimoldi OJ, Becú D, Zucolilli G, Portiansky E, Goya RG: IGF-I gene therapy in the brain of senile rats with dopaminergic neurodegeneration (abstract). Invited Symposium, 18th World Congress of Gerontology, Rio de Janeiro, 2005.

$25 \mathrm{Hu} \mathrm{N}$, Gutsmann A, Herbert DC, Bradley A, Lee WH, Lee EY: Heterozygous Rb-1 delta $20 /+$ mice are predisposed to tumors of the pituitary gland with a nearly complete penetrance. Oncogene 1994;9:1021-1029.

26 Riley DJ, Yu A, Lee W-H: Adenovirus-mediated retinoblastoma gene therapy suppresses spontaneous pituitary melanotroph tumors in $\mathrm{Rb}^{+/-}$mice. Nature Med 1996;2:1316-1321.

27 Windeatt S, Southgate TD, Dewey RA, Bolognani F, Perone MJ, Larregina AT, Maleniak TC, Morris ID, Goya RG, Klatzmann D, Lowenstein PR, Castro MG: Adenovirus-mediated herpes simplex virus type-1 thymidine kinase gene therapy suppresses oestrogen-induced pituitary prolactinomas. J Clin Endocrinol Metab 2000;85:1296-1305.

Rodolfo G. Goya

INIBIOLP, Faculty of Medicine, UNLP, CC 455

1900 La Plata (Argentina)

Tel. +54 221425 6735, Fax +54 221425 0924/4258988

E-Mail goya@isis.unlp.edu.ar/rgoya@netverk.com.ar 